\title{
Isolation and characterisation of an unexpected byproduct in the regioselective butane diacetal protection of $\alpha$-methyl galactopyranoside
}

Clément Q. Fontenelle, Ramakrishna Kuppala, Mark Light, and Bruno Linclau* Chemistry, University of Southampton, Highfield, Southampton SO17 1BJ, UK bruno.linclau@soton.ac.uk

\begin{abstract}
The regioselective protection of both methyl galactopyranoside anomers at the 2 and 3-positions as the butane diacetal (BDA) is well known. Here we describe the formation of an unexpected byproduct, which mainly occurs when $\alpha$-methyl galactopyranoside is reacted with 2,3-butanedione under $\mathrm{BF}_{3} \cdot \mathrm{OEt}_{2}$ catalysis. The structure of the byproduct, which did not arise from anomerisation to the $\beta$-anomer or from BDA formation at the galactopyranoside 3,4-positions, , was elucidated by NMR and X-ray crystallographic analysis, and proved to be the expected BDA protected galactopyranoside, but in which the stereochemistry of both its BDA acetal centres are inverted. Interestingly, the conformation of the resulting six-membered BDA ring was distorted to a skew boat conformation in order to maintain anomeric stabilisation.
\end{abstract}

Keywords: galactose, butane diacetal, regioselective protection, conformation

\section{Graphical abstract:}

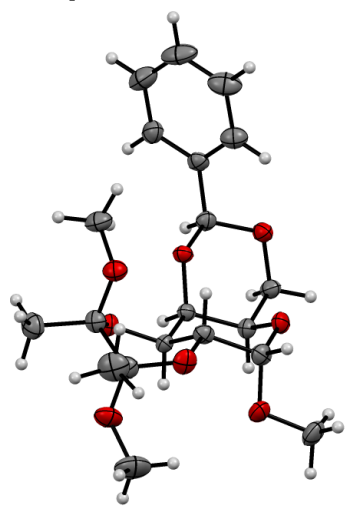

\section{Highlights:}

- selective butane diacetal protection of methyl galactopyranoside

- characterisation of a byproduct

- twist-boat butane diacetal conformation

- anomeric effect is the cause of significant six-membered ring deformation 


\section{Introduction}

The ability to achieve regioselective functionalisation of polyfunctional substrates is a key feature in synthetic chemistry. In the case of carbohydrates, there is a large body of synthetic methodology allowing for regioselective protection. In this regard, the butane diacetal protecting group, which is selective for vicinal diequatorial diols, is widely used. ${ }^{1,2}$ Hence, the protection of galactopyranoside is selective for the 2,3-diol moiety, in favour over the 3,4-position..$^{3,4,5,6,7,8,9}$ Under the typically employed acidcatalysed conditions using camphorsulfonic acid (CSA), (Scheme 1), acetal formation with 2,3-butanedione 1 in methanol, with trimethyl orthoformate as water capturing agent, both $\alpha$ - and $\beta$-methyl galactopyranosides 2 and $\mathbf{3}$ were reported to lead to the corresponding 2,3-protected BDA-products $\mathbf{4}$ and $\mathbf{5}$, with yields between 64 and $85 \%$. The use of $\mathrm{BF}_{3} \cdot \mathrm{OEt}_{2}$ as Lewis-acid was also described for the selective protection of $\beta$-methyl galactoside, in $85 \%$ yield. ${ }^{5}$ The selectivity for a diequatorial vicinal diol originates from the formation of a doubly anomerically stabilised BDA ring as shown in Scheme 1.

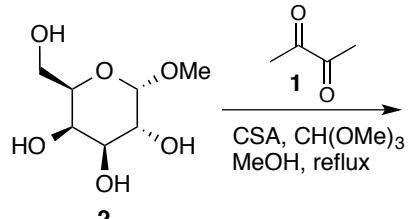

2

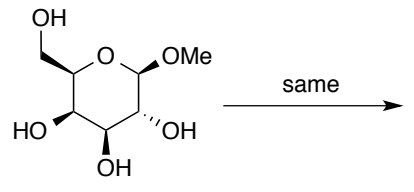

3
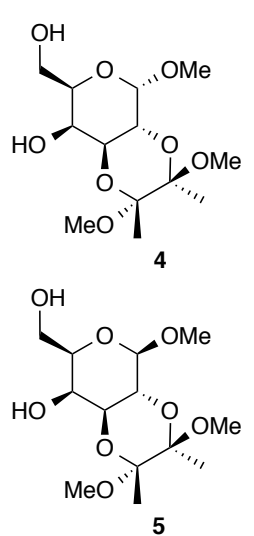
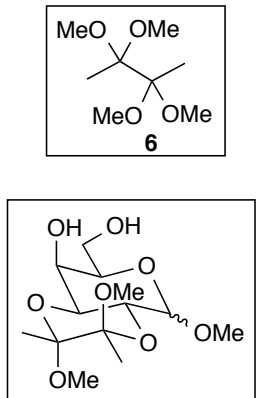

Scheme 1. Regioselective BDA protection of methyl galactopyranosides.

While these reports describe isolation of $4 / 5$ after chromatography, the formation of side products such as the corresponding 3,4-BDA regioisomer, or the anomerisation product at the methyl galactopyranoside acetal centre was never reported. The only exception is a report indicating that with $\alpha$-methyl galactopyranoside as substrate, the use of 2,2,3,3- tetramethoxybutane 6 as reagent (instead of 2,3-butanedione 1), the 2,3 -BDA adduct 4 was isolated $(54 \%)$ as a $10: 1$ mixture of $\alpha, \beta$-anomers. ${ }^{4}$

\section{Results and Discussion}

In our hands, protection of methyl $\alpha$-D-galactoside 2 using either $\mathrm{BF}_{3} \cdot \mathrm{OEt}_{2}$ or $\mathrm{CSA}$ successfully led to the desired product 4 (65-78\% yield). However, in both cases the formation of a number of byproducts was observed, with a higher $R_{f}$ than 4 , which were difficult to remove by column chromatography. A non-negligible major byproduct could only be isolated as a mixture with $\mathbf{4}$, and NMR analysis could only reveal that the $\beta$-anomer 5 was not present.

To avoid a difficult separation on multigram scale, the mixture was subjected to benzylidene protection using standard conditions (Scheme 2). Fortunately, this led to two products with a very different retention factor $(0.68$ and 0.28 ; petroleum 
ether/EtOAc). A benzylidene acetal formation experiment on a "pure" mixture of 4 and the major byproduct (a fraction obtained by column chromatography) led to a mixture of two benzylidene acetal containing products in the same ratio. The NMR analysis readily identified the major compound as the expected acetal $\mathbf{7}$, a known compound. ${ }^{7}$ For the pure byproduct 8 , NMR analysis showed that the anomeric substituent had remained in the $\alpha$-configuration, and that the BDA group was located at positions 2 and 3 . The ${ }^{1} \mathrm{H}-{ }^{13} \mathrm{C} \mathrm{HMBC}$ spectrum revealed a correlation between the benzylidene acetal proton and the carbon atoms at the 4- and 6-position, confirming the benzylidene acetal was present as a 6-membered ring at these positions. The ${ }^{1} \mathrm{H}$ ${ }^{13} \mathrm{C} \mathrm{HMBC}$ spectrum also showed cross-peaks between $\mathrm{H} 1$ and $\mathrm{C} 5$, further indicating that the galactopyranoside ring structure was maintained.<smiles>CO[C@H]1O[C@H](CO)[C@@H](O)[C@H](O)[C@H]1O</smiles>

2
1) $1, \mathrm{HC}(\mathrm{OMe})_{3}$ $\mathrm{BF}_{3} \cdot \mathrm{Et}_{2} \mathrm{O}$ $\mathrm{MeOH}, \mathrm{rt}, 20 \mathrm{~h}$

2) $\mathrm{PhCH}(\mathrm{OMe})_{2}$ CSA or PTSA $\mathrm{MeCN}, 80^{\circ} \mathrm{C}, 0.5 \mathrm{~h}$<smiles>CO[C@H]1O[C@@H]2CO[C@@H](c3ccccc3)O[C@H]2[C@H]2OC(C)(C)[C@](C)(OC)O[C@H]12</smiles>

7<smiles>CO[C@H]1O[C@@H]2CO[C@@H](c3ccccc3)O[C@H]2[C@H]2OC(C)(C)[C@@](C)(OC)O[C@H]12</smiles>

8

Scheme 2. BDA protection, followed by benzylidene acetal formation of a-methyl galactoside allowed separation of the byproduct 8 .

Fortunately, 8 proved crystalline, and its structure was elucidated by X-ray crystallographic analysis of suitable single crystals. Indeed, the configuration of both BDA acetal centers was found to be inverted compared to the compound 7 . However, stabilisation through the anomeric effect still operates, with both methoxy groups in pseudo-axial position, leading to a deformation of the bisacetal ring to a twist-boat conformation, while both the galactoside and benzylidene rings still adopt a chair conformation (Figure 1).

a)

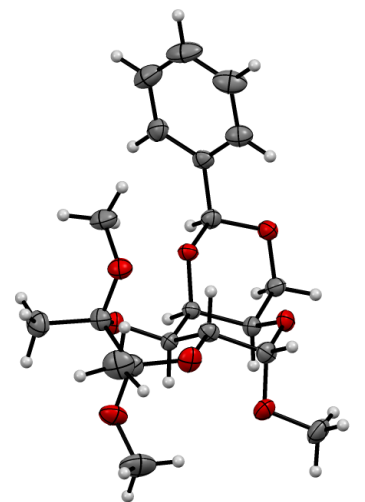

b)

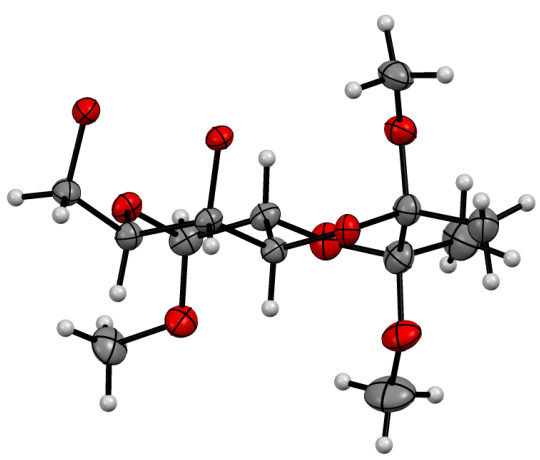

Figure 1: a) Crystal structure of 8. b) view of the twist boat BDA-ring conformation (the benzylidene group is removed for clarity).

Additional NMR experiments showed that this conformation is maintained in solution $\left(\mathrm{CDCl}_{3}\right)$. A cross-peak between $\mathrm{H}-3$ and $\mathrm{H}-5$ (a, Figure 2 ) were observed on the $2 \mathrm{D}$ ${ }^{1} \mathrm{H}-{ }^{1} \mathrm{H}$ NOESY spectrum, consistent with a ${ }^{4} \mathrm{C}_{1}$ pyranoside conformation. A crosspeak between the benzylidene acetal proton and $\mathrm{H}-4$ and $\mathrm{H}-6 \mathrm{ax}(\mathrm{b})$ further indicated 
that the benzylidene acetal ring adopted a chair conformation, with an equatorial phenyl ring. Furthermore, when irradiating $\mathrm{H} 2$ or $\mathrm{H} 3$ for both isomers $\mathbf{7}$ and $\mathbf{8}$, only a very small correlation could be observed with the methyl groups of the bisacetal. Interestingly, a cross-peak (c) could be observed between the ortho aromatic protons and one OMe group for the minor isomer 8 only, allowing for assignment of the BDA OMe groups. Structurally, this correlation is only possible with this OMe group in axial position. Furthermore, a more significant correlation (d) could be witnessed between the same OMe group with $\mathrm{H} 2$, and with the other OMe group and $\mathrm{H} 3$ (e). This is in agreement with an axial position for the two methoxy groups with the methyl groups in equatorial position.

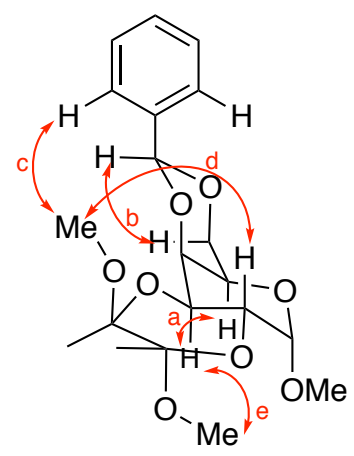

Figure 2. nOe's in 8.

A striking feature of the ${ }^{1} \mathrm{H}$ NMR spectra is also the chemical shift difference of $\mathrm{H}-2$ and $\mathrm{H}-3$ in compounds 7 and 8 . Their respective chemical shift is at $\delta=4.37$ and $4.22 \mathrm{ppm}$ in 7 while these are significantly deshielded at $\delta=4.75$ and $4.65 \mathrm{ppm}$ in 8 .

To the best of our knowledge, there is only one confirmed case of a double BDA diastereomeric byproduct. Dilmaç et al report a crystal structure of 10 (Figure 3), which was obtained by treating the corresponding triol with 2,2,3,3tetramethoxybutane, trimethyl orthoformate and CSA. ${ }^{10}$ Interestingly, these authors report that after 1 week of reaction, the ratio of $\mathbf{9}$ and $\mathbf{1 0}$ was 4:1 in favour of $\mathbf{1 0}$, while after two weeks, this had changed to $4: 1$ in favour of $\mathbf{9}$, suggesting that 10 is the kinetic isomer, and $\mathbf{9}$ is the thermodynamic one.
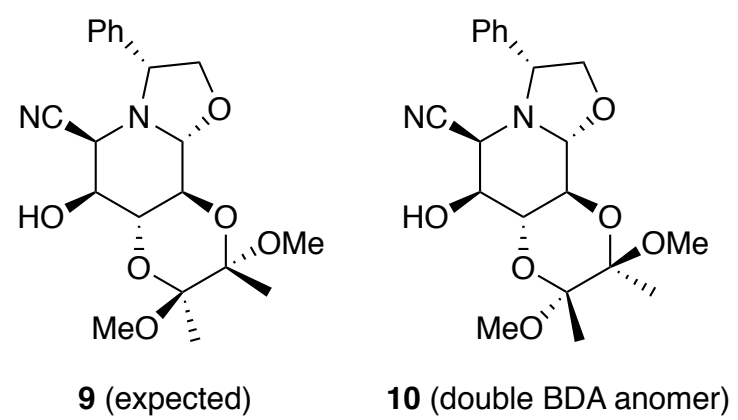

Figure 3. The literature example of a double BDA anomeric product. $^{10}$

The mixture obtained after BDA protection was heated with a catalytic amount of $p$ TSA in $\mathrm{MeOH}$ at $60{ }^{\circ} \mathrm{C}$ for 21 hours to attempt isomerisation of the BDA acetal groups. Although TLC analysis showed the disappearance of the byproduct, the yield 
of 7 was not improved after subsequent benzylidene protection. In fact, 7 was obtained as an 86:14 mixture, not with 8 , but with the $\beta$-methyl galactoside anomer (not shown), a result which resembles that obtained by Montchamp et al. ${ }^{4}$ Unfortunately, under $\mathrm{BF}_{3}$-catalysis, prolonging the reaction time of the BDA protection did not lead to an increase in yield (after subsequent benzylidene protection), though the amount of $\mathbf{8}$ was substantially lower.

\section{Conclusion}

In conclusion, we report on a hitherto unidentified byproduct of the BDA-protection of methyl $\alpha$-galactopyranoside 1 . It was shown that purification and isolation is very straightforward upon subsequent benzylidene protection. Interestingly, the byproduct arose from inversion of the BDA acetal centres, and not from galactoside anomerisation centre, or from regioisomeric BDA protection. Both X-ray crystallographic and NMR analysis show distortion of the BDA six-membered ring, evidently in order to allow maximal anomeric stabilisation by axially oriented OMe groups. To minimise formation of this byproduct, BDA protection of $\mathbf{2}$ is recommended under CSA catalysis with sufficient reaction time and temperature.

\section{Experimental section}

\subsection{Synthesis}

Methyl 4,6-O-benzylidene-2,3-O-((2'R,3'R)-2',3'-dimethoxybutane-2',3'-diyl)- $\alpha-D-$ galactopyranoside 7 and methyl 4,6-O-benzylidene-2,3-O-((2'S,3'S)-2',3'dimethoxybutane-2',3'-diyl)- $\alpha$-D-galactopyranoside 8.

$\mathrm{BF}_{3} \bullet \mathrm{Et}_{2} \mathrm{O}$ (1.11 mL, $8.96 \mathrm{mmol}, 0.1$ equiv) was added to a solution of methyl $\alpha$-Dgalactopyranoside (17.4 g, $89.6 \mathrm{mmol}, 1$ equiv), 2,3-butanedione (8.61 mL, 98.6 mmol, 1.1 equiv) and trimethyl orthoformate $(39.2 \mathrm{~mL}, 358 \mathrm{mmol}, 4$ equiv) in dry $\mathrm{MeOH}(90 \mathrm{~mL})$. The reaction mixture was stirred at room temperature for $20 \mathrm{~h}$ then neutralised by the addition of $\mathrm{Et}_{3} \mathrm{~N}(1.37 \mathrm{~mL}, 9.86 \mathrm{mmol}, 0.11$ equiv) before concentration under reduced pressure. Part of the crude product obtained $(11.1 \mathrm{~g}$, $36.0 \mathrm{mmol}, 1$ equiv) was dissolved in $\mathrm{MeCN}(111 \mathrm{~mL})$ and benzaldehyde dimethyl acetal $(5.7 \mathrm{~mL}, 37.8 \mathrm{mmol}, 1.05$ equiv) was added followed by $\mathrm{TsOH}(0.342 \mathrm{~g}, 1.80$ mmol, 0.05 equiv). The reaction mixture was heated at $80^{\circ} \mathrm{C}$ for $1 \mathrm{~h}$ then neutralised with $\mathrm{Et}_{3} \mathrm{~N}(0.375 \mathrm{~mL}, 2.70 \mathrm{mmol}, 0.075$ equiv) and concentrated. Column chromatography (petroleum ether 40-60 ${ }^{\circ} \mathrm{C} /$ EtOAc 75:25 to 50:50) gave the minor and major products as yellow solids. Recrytallisation from hexane/EtOAc afforded $7.15 \mathrm{~g}(18.0 \mathrm{mmol}, 50 \%)$ of 7 as white fibres and $1.12 \mathrm{~g}(2.83 \mathrm{mmol}, 8 \%)$ of 8 as colourless crystals.

Data for 8: m.p. $152-154{ }^{\circ} \mathrm{C}$. $[\alpha]_{\mathrm{D}}+200.3$ (c $0.507, \mathrm{CHCl}_{3}, 22{ }^{\circ} \mathrm{C}$ ). $R_{\mathrm{f}} 0.68$ (petroleum ether 40-60 $\left.{ }^{\circ} \mathrm{C} / \mathrm{EtOAc} 65: 35\right) .{ }^{1} \mathrm{H}$ NMR $\left(400 \mathrm{MHz}, \mathrm{CDCl}_{3}\right) \delta 7.56-7.48\left(\mathrm{~m}, 2 \mathrm{H}, \mathrm{H}_{\mathrm{Ar}}\right)$, 7.37 - $7.29\left(\mathrm{~m}, 3 \mathrm{H}, \mathrm{H}_{\mathrm{Ar}}\right), 5.57(\mathrm{~s}, 1 \mathrm{H}, \mathrm{CHPh}), 4.95(\mathrm{~d}, J=3.3 \mathrm{~Hz}, 1 \mathrm{H}, \mathrm{H}-1), 4.75$ (dd, J $=11.7,3.3 \mathrm{~Hz}, 1 \mathrm{H}, \mathrm{H}-2), 4.65(\mathrm{dd}, J=11.7,3.3 \mathrm{~Hz}, 1 \mathrm{H}, \mathrm{H}-3), 4.25$ (dd, $J=12.5,1.4$ $\mathrm{Hz}, 1 \mathrm{H}, \mathrm{H}-6$ ), 4.25 (br d, J = 3.3 Hz, 1H, H-4), 4.08 (dd, J=12.5, 1.6 Hz, 1H, H-6'), 3.66 - $3.62(\mathrm{~m}, 1 \mathrm{H}, \mathrm{H}-5), 3.46\left(\mathrm{~s}, 3 \mathrm{H}, \mathrm{C}-1-\mathrm{OCH}_{3}\right), 3.41$ (s, 3H, OCH$\left.{ }_{3}{ }^{\prime} \mathrm{BDA}\right), 3.26$ (s, $3 \mathrm{H}, \mathrm{OCH}_{3}{ }^{3} \mathrm{BDA}$ ), 1.37 (s, 3H, $\left.\mathrm{CH}_{3}{ }^{2} \mathrm{BDA}\right), 1.36$ (s, 3H, $\left.\mathrm{CH}_{3}{ }^{3} \mathrm{BDA}\right) \mathrm{ppm} .{ }^{13} \mathrm{C} \mathrm{NMR}$ $\left(101 \mathrm{MHz}, \mathrm{CDCl}_{3}\right) \delta 138.0\left(\mathrm{C}_{\mathrm{q}, \mathrm{Ar}}\right), 128.9\left(\mathrm{CH}_{\mathrm{Ar}}\right), 127.9\left(2 \mathrm{C}, \mathrm{CH}_{\mathrm{Ar}}\right), 126.3\left(2 \mathrm{C}, \mathrm{CH}_{\mathrm{Ar}}\right)$, 101.4 (2C, $\left.\mathrm{C}_{\mathrm{q}, \mathrm{BDA}}\right), 100.9$ (CHPh), 99.6 (C-1), 74.7 (C-4), 69.6 (C-6), 68.0 (C-2), 67.9 (C-3), 62.8 (C-5), $55.6\left(\mathrm{C}-1-\mathrm{OCH}_{3}\right), 48.14\left(\mathrm{OCH}_{3}{ }^{{ }^{\prime}} \mathrm{BDA}\right), 48.06\left(\mathrm{OCH}_{3}{ }^{{ }^{\prime}} \mathrm{BDA}\right), 19.0$ 
$\left(\mathrm{CH}_{3} \mathrm{BDA}\right), 19.0\left(\mathrm{CH}_{3} \mathrm{BDA}\right) \mathrm{ppm}$. MS (ESI+) m/z $419(\mathrm{M}+\mathrm{Na})^{+}$. HRMS (ES+) for $\mathrm{C}_{20} \mathrm{H}_{28} \mathrm{NaO}_{8}(\mathrm{M}+\mathrm{Na})+$, calcd 419.1676, found 419.1677.

\subsection{X-ray crystallography}

Data were recorded on a Rigaku R-AXIS Spider diffractometer following standard procedures. Crystal Data: $\mathrm{C}_{20} \mathrm{H}_{28} \mathrm{O}_{8}, M_{r}=396.42$, monoclinic, $\mathrm{P} 2{ }_{1}$ (No. 4), $\mathrm{a}=$ 7.8663(3) $\AA, b=11.6341(4) \AA, c=11.5711(4) \AA, \beta=106.713(7)^{\circ}, \alpha=\gamma=90^{\circ}, V=$ 1014.22(7) $\AA^{3}, T=150(2) \mathrm{K}, Z=2, Z^{\prime}=1, \mu\left(\mathrm{CuK}_{a}\right)=0.838,11326$ reflections measured, 3424 unique $\left(R_{\text {int }}=0.0764\right)$ which were used in all calculations. The final $w R_{2}$ was 0.0836 (all data) and $R_{1}$ was $0.0356(\mathrm{I}>2(\mathrm{I})$ ).

\section{Supplementary data}

Complete crystallographic data for the structural analysis have been deposited with the Cambridge Crystallographic Data Centre, CCDC 542719. Copies of this information may be obtained free of charge from the Director, Cambridge Crystallographic Data Centre, 12 Union Road, Cambridge, CB2 1EZ, UK. (fax: +441223-336033, e-mail: deposit@ccdc.cam.ac.uk or via:

www.ccdc.cam.ac.uk/structures.

\section{Acknowledgements}

This project has been funded by the Industrial Biotechnology Catalyst (Innovate UK, BBSRC, EPSRC, BB/M028941/1) to support the translation, development and commercialization of innovative Industrial Biotechnology processes. We also thank the EPSRC (core capability EP/K039466/1) for funding.

(1) Ley, S. V.; Baeschlin, D. K.; Dixon, D. J.; Foster, A. C.; Ince, S. J.; Priepke, H. W. M.; Reynolds, D. J. Chem. Rev. 2001, 101, 53.

(2) Ley, S. V.; Polara, A. J. Org. Chem. 2007, 72, 5943.

(3) Douglas, N. L.; Ley, S. V.; Osborn, H. M. I.; Owen, D. R.; Priepke, H. W. M.; Warriner, S. L. Synlett 1996, 793.

(4) Montchamp, J. L.; Tian, F.; Hart, M. E.; Frost, J. W. J. Org. Chem. 1996, 61, 3897.

(5) Hense, A.; Ley, S. V.; Osborn, H. M. I.; Owen, D. R.; Poisson, J. F.; Warriner, S. L.; Wesson, K. E. Journal of the Chemical Society-Perkin Transactions $11997,2023$.

(6) Ley, S. V.; Owen, D. R.; Wesson, K. E. Journal of the Chemical SocietyPerkin Transactions 1 1997, 2805.

(7) Herczeg, M.; Demeter, F.; Mező, E.; Pap, M.; Borbás, A. Eur. J. Org. Chem. 2015, 2015, 5730.

(8) Liu, D.; He, W. G.; Wang, Z. H.; Liu, L.; Wang, C. Q.; Zhang, C. X.; Wang, C. C.; Wang, Y. X.; Tanabe, G.; Muraoka, O.; Wu, X. M.; Wu, L.; Xie, W. J. European Journal of Medicinal Chemistry 2016, 110, 224.

(9) Puchner, C.; Eixelsberger, T.; Nidetzky, B.; Brecker, L. Carbohydr. Res. 2017, 437, 50.

(10) Dilmac, A. M.; Tite, T.; Tsimilaza, A.; Lemoine, P.; Boutefnouchet, S.; Michel, S.; Lallemand, M. C. Arkivoc 2014, 24. 
